Article

\title{
Chermebilaenes A and B, New Bioactive Meroterpenoids from Co-Cultures of Marine-Derived Isolates of Penicillium bilaiae MA-267 and Penicillium chermesinum EN-480
}

\author{
Ling-Hong Meng ${ }^{1,2, *}$, Xiao-Ming Li ${ }^{1,2} \mathbb{0}$, Hong-Lei $\mathrm{Li}^{1,2}{ }^{10}$ and Bin-Gui Wang ${ }^{1,2,3, * \mathbb{C}}$ \\ 1 Key Laboratory of Experimental Marine Biology, Institute of Oceanology, Chinese Academy of Sciences, \\ Nanhai Road 7, Qingdao 266071, China; lixmqdio@126.com (X.-M.L.); lihonglei428@126.com (H.-L.L.) \\ 2 Laboratory of Marine Biology and Biotechnology, Qingdao National Laboratory for Marine Science and \\ Technology, Wenhai Road 1, Qingdao 266237, China \\ 3 Center for Ocean Mega-Science, Chinese Academy of Sciences, Nanhai Road 7, Qingdao 266071, China \\ * Correspondence: menglh@ms.qdio.ac.cn (L.-H.M.); wangbg@ms.qdio.ac.cn (B.-G.W.); \\ Tel.: +86-532-8289-8890 (L.-H.M.); +86-532-8289 8553 (B.-G.W.)
}

Received: 10 June 2020; Accepted: 26 June 2020; Published: 28 June 2020

\begin{abstract}
The co-cultivation of two or more different microbial strains in one culture vessel was supposed to be a viable experimental approach for enhancing the diversity of the compounds produced. Two new meroterpenoid derivatives, chermebilaenes A (1) and B (2), together with three known sesquiterpenoids, sesquicaranoic acid B (3), cyclonerodiol (4) and bisabol-1-on-13-säuremethylester (5), were characterized from a co-culture of the marine-derived fungal isolates of Penicillium bilaiae MA-267 and Penicillium chermesinum EN-480. Neither fungus produced these compounds when cultured alone under the same conditions. Compound 1 represents an unprecedented acorane-type sesquiterpene hybridized with an octadecadienoic acid skeleton. The structures were elucidated on the basis of spectroscopic analysis, and the absolute configurations were assumed on the basis of acidic hydrolysis combined with modified Mosher's method and electronic circular dichroism (ECD) calculations. Compound $\mathbf{1}$ showed potent inhibitory activities against Ceratobasidium cornigerum and Edwardsiella tarda.
\end{abstract}

Keywords: Penicillium chermesinum; Penicillium bilaiae; co-culture; secondary metabolites; antimicrobial activity

\section{Introduction}

Marine fungi are able to synthesize a wide range of structurally unique secondary metabolites endowed with numerous biological activities [1-3]. However, mining the full-genome sequences of fungi demonstrates their potential to produce many more compounds than previously expected. It is well recognized that most of the microbial biosynthesis gene clusters remain silent and are apparently not transcribed under conventional cultivation conditions $[4,5]$. The co-cultivation of two or more different microbial strains in one culture vessel was supposed to be a viable experimental approach for enhancing the diversity of the compounds produced [6-8]. In our efforts to identify new bioactive secondary metabolites from marine-derived fungi, we previously investigated the secondary metabolites of two strains of the fungal genus Penicillium, namely P. bilaiae MA-267 and P. chermesinum EN-480, from which several sesquiterpenes with a tricyclo $\left(6.3 .1 .0^{1,5}\right)$ dodecane skeleton [9], spiromeroterpenoids containing a drimane-type sesquiterpene skeleton [10], and sesquiterpenoids [11] have been isolated, respectively. In order to investigate the chemical potential of P. bilaiae MA-267 and P. chermesinum 
EN-480, we initiated the co-culture fermentation of these two fungal strains, which showed the production of several metabolites that were not produced when the two fungi were cultured alone (Figure S23, Supplementary Material). As a result, chermebilaene A (1), the first natural sesquiterpene hybridized with octadecadienoic acid, together with a new orthoester meroterpenoid, chermebilaene B (2), as well as three known sesquiterpenoids, sesquicaranoic acid B (3), cyclonerodiol (4) and bisabol-1-on-13-säuremethylester (5) (Figure 1), were isolated from the co-culture extract of P. bilaiae MA-267 and P. chermesinum EN-480. Herein, details of the isolation, structure determination, and biological activities of these compounds are described.

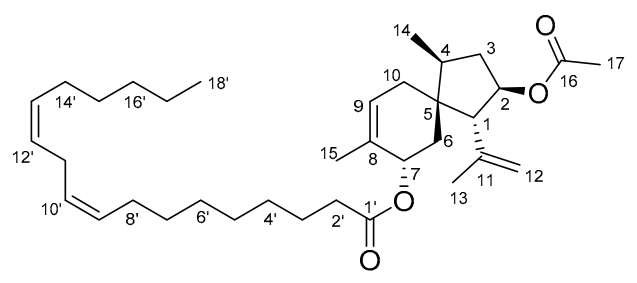

1

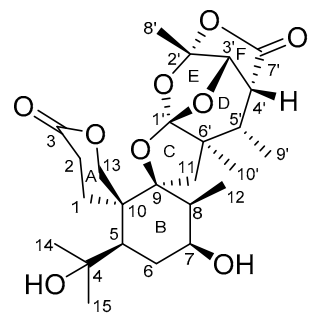

2<smiles>COC(=O)/C(C)=C\CC[C@H]1CCC(C)=CC1=O</smiles>

Figure 1. Structures of compounds 1-5.

\section{Results and Discussion}

\subsection{Structure Elucidation of the New Compounds}

Chermebilaene A (1) was isolated as a colorless oil. Its molecular formula was determined as $\mathrm{C}_{35} \mathrm{H}_{56} \mathrm{O}_{4}$ by (+)-HRESIMS (high resolution electrospray ionization mass spectroscopy) data (Figure $\mathrm{S} 1$, Supplementary Material), implying eight degrees of unsaturation (index of hydrogen deficiency). Analysis of the ${ }^{1} \mathrm{H}$ NMR spectrum (Table 1 ) and HSQC data revealed the presence of five methyl signals at $\delta_{\mathrm{H}} 1.76(\mathrm{H}-13,3 \mathrm{H}, \mathrm{s}), 1.08(\mathrm{H}-14,3 \mathrm{H}, \mathrm{d}, J=7.1 \mathrm{~Hz}), 1.63(\mathrm{H}-15,3 \mathrm{H}, \mathrm{s}), 2.00(\mathrm{H}-17,3 \mathrm{H}, \mathrm{s})$, and 0.89 $\left(\mathrm{H}-18^{\prime}, 3 \mathrm{H}, \mathrm{t}, J=6.8 \mathrm{~Hz}\right)$, five olefinic methines $5.49(\mathrm{H}-9,1 \mathrm{H}, \mathrm{dd}, J=3.3,1.8 \mathrm{~Hz}), 5.40\left(\mathrm{H}-9^{\prime} / 13^{\prime}, 2 \mathrm{H}, \mathrm{dd}\right.$, $J=10.9,5.5 \mathrm{~Hz}), 5.34\left(\mathrm{H}-10^{\prime} / 12^{\prime}, 2 \mathrm{H}, \mathrm{dd}, J=10.9,6.5 \mathrm{~Hz}\right)$, and two oxymethines $5.21(\mathrm{H}-2,1 \mathrm{H}, \mathrm{td}, J=8.6$, $4.2 \mathrm{~Hz})$ and $5.38(\mathrm{H}-7,1 \mathrm{H}, \mathrm{m})$, as well as a terminal methylene resonating at $\delta_{\mathrm{H}} 4.69$ and $4.98(\mathrm{H}-12,2 \mathrm{H}$, s). In addition, several unresolved methylene signals at $\delta_{\mathrm{H}} 1.31$, attributable to the protons of a long unbranched carbon chain, were also present. The ${ }^{13} \mathrm{C}$ NMR data along with the DEPT (distortionless enhancement by polarization transfer) spectra revealed the presence of 35 carbon atoms, including five nonprotonated carbons (with two olefinic and two carbonyl), nine methines (with five olefinic and two oxygenated aliphatic), sixteen methylenes (with one terminal), and five methyls. Detailed analysis of the NMR data disclosed the structure of $\mathbf{1}$ to possess an acorane-type sesquiterpenoid residue linked with an octadecadienoic acid through esterification. Specifically, the ${ }^{1} \mathrm{H}$ and ${ }^{13} \mathrm{C}$ chemical shifts for the left portion of 1 were nearly identical to those of the 9,12-octadecadienoic acid [12], while for the right portion, quite similar to those of the adametacorenol $\mathrm{A}$, an acorane sesquiterpene derivative was obtained from the rice culture broth of a marine-derived fungus, Penicillium adametzioides AS-53 [13]. However, signals for the oxygenated methine resonating at $\delta_{\mathrm{C} / \mathrm{H}} 66.4 / 3.96(\mathrm{CH}-7)$ in adametacorenol A [13] were deshielded at $\delta_{\mathrm{C} / \mathrm{H}} 71.3 / 5.38(\mathrm{CH}-7)$ in the NMR spectra of compound 1 , while the chemical shift of carboxyl resonating at $\delta_{\mathrm{C}} 178.4(\mathrm{C}-1)$ in 9,12-octadecadienoic acid [9] shifted upfield at $\delta_{\mathrm{C}}$ $173.8\left(\mathrm{C}-1^{\prime}\right)$ in 1 due to the esterification effect. In addition, signals for the ortho- and meta-positions resonating at $\delta_{\mathrm{C}} 136.6(\mathrm{C}-8)$ and $\delta_{\mathrm{C} / \mathrm{H}} 120.9 / 5.25(\mathrm{CH}-9)$ in adametacorenol A [13] moved to $\delta_{\mathrm{C}} 132.1$ $(\mathrm{C}-8)$ and $\delta_{\mathrm{C} / \mathrm{H}} 125.3 / 5.49(\mathrm{CH}-9)$ in $\mathbf{1}$, respectively. This deduction was further supported by the COSY 
and HMBC correlations (Figure 2). This is the first time that this type of meroterpenoid, which contains an unprecedented acorane-type sesquiterpene hybridized with octadecadienoic acid skeleton, has been described.
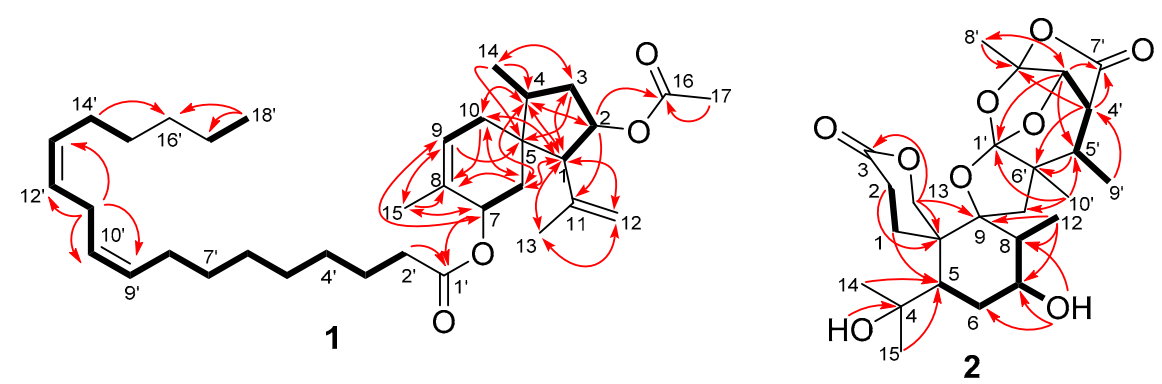

Figure 2. Key COSY (homonuclear chemical shift correlation spectroscopy) (bold line) and HMBC (heteronuclear multiple bond correlation) (arrow) correlations of compounds $\mathbf{1}$ and 2.

The relative configuration of 1 was determined by the analysis of the $J$-values and NOESY (nuclear overhauser effect spectroscopy) data (Figure 3). The coupling constants between H-9'/13' and H-10'/12' $(10.9 \mathrm{~Hz})$ suggested the geometry of the $\mathrm{C}=\mathrm{C}$ bond at $\mathrm{C}-9^{\prime}$ and $\mathrm{C}-13^{\prime}$ to be $\mathrm{Z}$. Moreover, NOE correlations from $\mathrm{H}_{3}-14$ to $\mathrm{H}-1, \mathrm{H}-6 \beta$, and $\mathrm{H}-7$, and from $\mathrm{H}-7$ to $\mathrm{H}-1$, suggested the same orientation of these groups, while the correlations from $\mathrm{H}-2$ to $\mathrm{H}-4$ placed these protons on the opposite face.
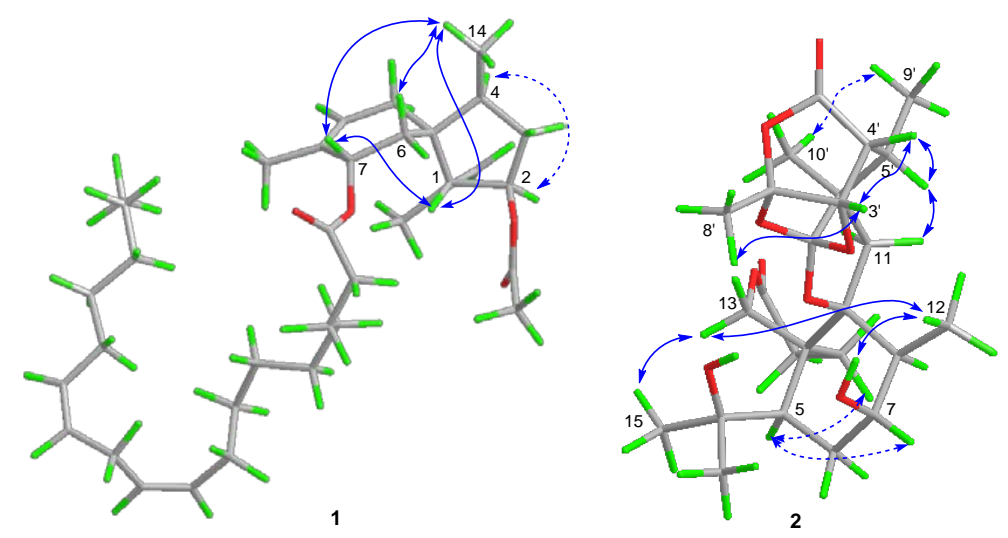

Figure 3. NOESY (nuclear overhauser effect spectroscopy) correlations of compounds $\mathbf{1}$ and $\mathbf{2}$.

To confirm the structure and absolute configuration of $\mathbf{1}$, we pursued a strategy consisting of the acidic hydrolysis of $\mathbf{1}$ to yield the sesquiterpene diol (6) and 9,12-octadecadienoic acid (7), followed by modified Mosher's method for the obtained 6, and NMR analysis of the resulting Mosher esters allowed the assignment of the $2 R$ and $7 S$ absolute configuration in compound 6 (Figure 4 ) and, consequently, the absolute configuration of compound 1 was deduced to be $1 R, 2 R, 4 S, 5 S$, and $7 S$.

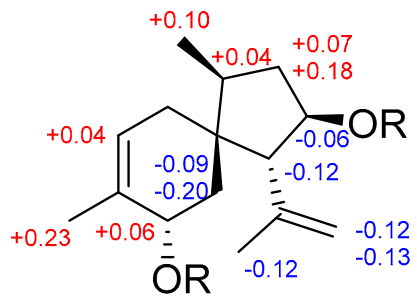

$\begin{array}{ll}6 & \mathrm{R}=\mathrm{H} \\ \text { 6a } & \mathrm{R}=(S)-M T P A \\ \text { 6b } & \mathrm{R}=(R)-M T P A\end{array}$

Figure 4. $\Delta \delta$ values $\left(\Delta \delta\right.$ (in ppm) $\left.=\delta_{S}-\delta_{R}\right)$ obtained for the (S)-and (R)-MTPA ( $\alpha$-methoxy$\alpha$-(trifluoromethyl) phenylacetyl) esters of compound 6 . 
Chermebilaene B (2) was isolated as a colorless, amorphous solid with a determined molecular formula of $\mathrm{C}_{25} \mathrm{H}_{36} \mathrm{O}_{9}$ (eight degrees of unsaturation) on the basis of (+)-HRESIMS (high resolution electrospray ionization mass spectroscopy) data. The ${ }^{1} \mathrm{H}$ and ${ }^{13} \mathrm{C}$ NMR spectroscopic data (Table 1) contained 25 carbon signals, which were sorted by DEPT and HSQC experiments into the following categories: six methyls, five methylenes (with one oxygenated), six methines (with two oxygenated), and eight quaternary carbons (with two carbonyl and four oxygenated), as well as two exchangeable protons. Detailed analysis of the ${ }^{1} \mathrm{H}$ and ${ }^{13} \mathrm{C}$ NMR spectroscopic data revealed that 2 was a spiromeroterpenoid derivative, similar to asnovolin $\mathrm{G}$ isolated from the fungus Aspergillus novofumigatus [14]. However, one of the methylenes resonating at $\delta_{\mathrm{C} / \mathrm{H}} 28.4 / 1.61\left(\mathrm{CH}_{2}-7\right)$ in asnovolin $\mathrm{G}$ was replaced by an oxymethine unit in 2 , as shown by the HRESIMS data as well as by the observation of additional resonance signals at $\delta_{\mathrm{C}} 67.0 / \delta_{\mathrm{H}} 3.71(\mathrm{CH}-7)$ and $\delta_{\mathrm{H}} 4.54(7-\mathrm{OH})$ in the NMR spectra of 2 (Table 2). The deduction was supported by the COSY and HMBC correlations (Figure 2).

The relative configuration was determined by the detailed analysis of the NOESY data (Figure 3). Key NOESY correlations from $\mathrm{H}-13 \alpha$ to $\mathrm{H}_{3}-15$ and $\mathrm{H}_{3}-12$, and from the protons of $7-\mathrm{OH}$ to $\mathrm{H}_{3}-12$, revealed the cofacial orientation of these groups, while the NOE cross-peaks from $\mathrm{H}-5$ to $\mathrm{H}-1 \alpha$ and $\mathrm{H}-7$ placed these groups on the opposite face, which determined the relative configuration of the A/B rings. Furthermore, the NOE correlations from $\mathrm{H}-3^{\prime}$ to $\mathrm{H}_{3}-8^{\prime}$ and $\mathrm{H}-4^{\prime}$, and from $\mathrm{H}-5^{\prime}$ to $\mathrm{H}-4^{\prime}$ and $\mathrm{H}-11 \beta$, indicated the cofacial orientation of these groups, while correlations from $\mathrm{H}_{3}-9^{\prime}$ to $\mathrm{H}_{3}-10^{\prime}$ placed the two methyls on the opposite face. The $\left(5 R^{*}, 7 S^{*}, 8 S^{*}, 9 S^{*}, 10 S^{*}, 1^{\prime} S^{*}, 2^{\prime} S^{*}, 3^{\prime} S^{*}, 4^{\prime} R^{*}, 5^{\prime} S^{*}, 6^{\prime} R^{*}\right)$ relative configuration could thus be deduced for 2 .

In order to determine the absolute configuration, a conformational search, DFT (density functional theory) optimizations, and TDDFT-ECD (Time-dependent density functional theory electronic circular dichroism) calculations using density functional theory (B3LYP/6-31G(d)) in Gaussian 09 [15] were performed on the arbitrarily chosen $\left(5 R^{*}, 7 S^{*}, 8 S^{*}, 9 S^{*}, 10 S^{*}, 1^{\prime} S^{*}, 2^{\prime} S^{*}, 3^{\prime} S^{*}, 4^{\prime} R^{*}, 5^{\prime} S^{*}, 6^{\prime} R^{*}\right)$-enantiomer of 2 . The ECD spectra that were computed for this enantiomer at various levels reproduced well the experimental ECD spectrum, allowing the elucidation of the absolute configuration as $5 R, 7 S, 8 S, 9 S$, $10 S, 1^{\prime} S, 2^{\prime} S, 3^{\prime} S, 4^{\prime} R, 5^{\prime} S, 6^{\prime} R$ (Figure 5).

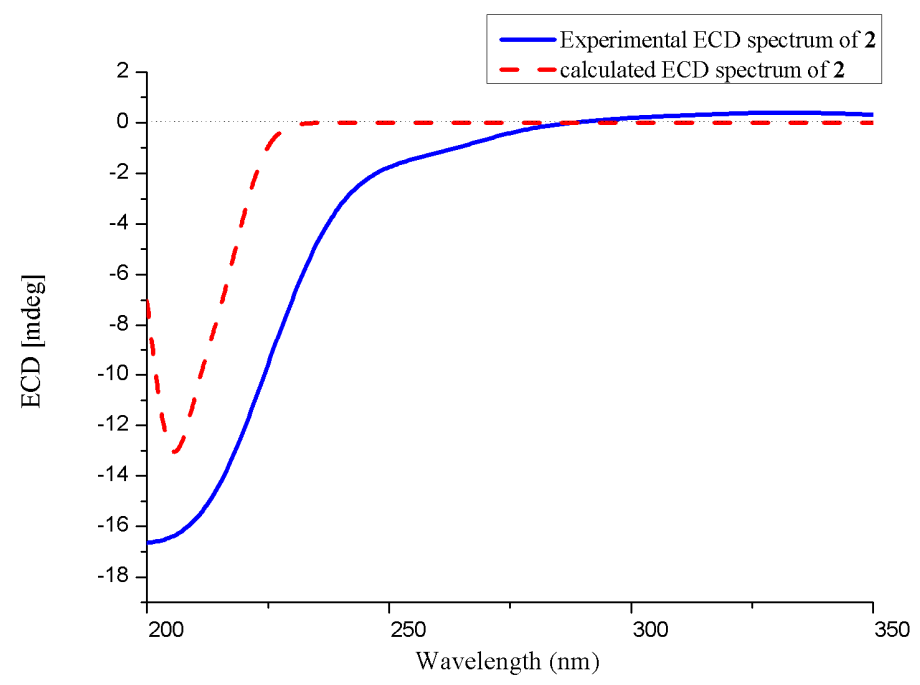

Figure 5. Experimental and calculated ECD (electronic circular dichroism) spectra of 2.

In addition to compounds 1 and 2, three known sesquiterpenoids, namely sesquicaranoic acid B (3) [16], cyclonerodiol (4) [17], and bisabol-l-on-13-säuremethylester (5) [18], were isolated and identified from the co-culture extract. Neither fungus produced these compounds when cultured alone under the same conditions. 
Table 1. ${ }^{1} \mathrm{H}(500 \mathrm{MHz})$ and ${ }^{13} \mathrm{C}$ NMR $(125 \mathrm{MHz})$ data of compounds 1-2.

\begin{tabular}{|c|c|c|c|c|}
\hline \multirow{2}{*}{ No. } & \multicolumn{2}{|c|}{1 (Acquired in $\mathrm{CDCl}_{3}$ ) } & \multicolumn{2}{|c|}{2 (Acquired in DMSO- $d_{6}$ ) } \\
\hline & $\delta_{\mathrm{H}}(J$ in $\mathrm{Hz})$ & $\delta_{\mathrm{C}}$ & $\delta_{\mathrm{H}}(J$ in $\mathrm{Hz})$ & $\delta_{\mathrm{C}}$ \\
\hline 1 & 2.74 , overlap & $57.4, \mathrm{CH}$ & $\begin{array}{c}\alpha 1.82, \text { ddd }(12.7,9.6,3.5) \\
\beta 2.71, \text { ddd }(12.7,10.3,6.3)\end{array}$ & $25.8, \mathrm{CH}_{2}$ \\
\hline 2 & $5.21, \operatorname{td}(8.6,4.2)$ & $77.8, \mathrm{CH}$ & $2.33, \mathrm{~m}$ & 29.3, $\mathrm{CH}_{2}$ \\
\hline 3 & $\begin{array}{l}\alpha 2.53, \mathrm{dt}(14.7,8.6) \\
\quad \beta 2.02, \text { overlap }\end{array}$ & $38.7, \mathrm{CH}_{2}$ & & $173.2, \mathrm{C}$ \\
\hline 4 & 2.02, overlap & $38.3, \mathrm{CH}$ & & 73.0, C \\
\hline 5 & & $46.9, \mathrm{C}$ & $1.33, \mathrm{dd}(12.6,2.3)$ & $49.0, \mathrm{CH}$ \\
\hline 6 & $\begin{array}{l}\alpha 1.66, \text { overlap } \\
\beta 2.02, \text { overlap }\end{array}$ & $31.9, \mathrm{CH}_{2}$ & $1.44, \mathrm{~m}$ & $29.1, \mathrm{CH}_{2}$ \\
\hline 7 & $5.38, \mathrm{~m}$ & $71.3, \mathrm{CH}$ & $3.71, \mathrm{dq}(10.0,4.0)$ & $67.0, \mathrm{CH}$ \\
\hline 8 & & 132.1, C & $2.39, \mathrm{~m}$ & $46.6, \mathrm{CH}$ \\
\hline 9 & $5.49, \mathrm{dd}(3.3,1.8)$ & 125.3, $\mathrm{CH}$ & & 92.1, C \\
\hline 10 & $\begin{array}{l}\alpha 1.70, \mathrm{dd}(13.1,3.3) \\
\beta 1.98, \mathrm{dd}(13.1,1.8)\end{array}$ & $34.8, \mathrm{CH}_{2}$ & & $44.7, \mathrm{C}$ \\
\hline 11 & & $142.8, \mathrm{C}$ & $\begin{array}{l}\alpha 2.04, \mathrm{~d}(13.9) \\
\beta 1.93, \mathrm{~d}(13.9)\end{array}$ & $49.7, \mathrm{CH}_{2}$ \\
\hline 12 & $\begin{array}{l}Z 4.69, \mathrm{~s} \\
E 4.98, \text { brs }\end{array}$ & $114.4, \mathrm{CH}_{2}$ & $0.90, \mathrm{~d}(7.2)$ & $10.2, \mathrm{CH}_{3}$ \\
\hline 13 & $1.76, \mathrm{~s}$ & $24.4, \mathrm{CH}_{3}$ & $\begin{array}{l}\alpha 4.47, \mathrm{~d}(12.2) \\
\beta 4.27, \mathrm{~d}(12.2)\end{array}$ & $66.7, \mathrm{CH}_{2}$ \\
\hline 14 & $1.08, \mathrm{~d}(7.1)$ & $17.6, \mathrm{CH}_{3}$ & $1.20, \mathrm{~s}$ & $34.3, \mathrm{CH}_{3}$ \\
\hline 15 & $1.63, \mathrm{~s}$ & $19.2, \mathrm{CH}_{3}$ & $1.15, \mathrm{~s}$ & $25.9, \mathrm{CH}_{3}$ \\
\hline 16 & & 171.0, C & & \\
\hline 17 & $2.00, \mathrm{~s}$ & $21.4, \mathrm{CH}_{3}$ & & \\
\hline $1^{\prime}$ & & $173.8, \mathrm{C}$ & & $128.0, \mathrm{C}$ \\
\hline $2^{\prime}$ & $2.32, \mathrm{t}(7.4)$ & 31.7, $\mathrm{CH}_{2}$ & & 107.2, C \\
\hline $3^{\prime}$ & 1.66 , overlap & $22.9, \mathrm{CH}_{2}$ & $5.03, \mathrm{~d}(8.5)$ & $77.5, \mathrm{CH}$ \\
\hline $4^{\prime}$ & 1.31 , overlap & $25.8, \mathrm{CH}_{2}$ & $2.82, \mathrm{dd}(8.5,6.1)$ & 41.3, $\mathrm{CH}$ \\
\hline $5^{\prime}$ & 1.31 , overlap & $27.4, \mathrm{CH}_{2}$ & $2.05, \mathrm{~m}$ & $40.1, \mathrm{CH}$ \\
\hline $6^{\prime}$ & 1.31 , overlap & $29.3, \mathrm{CH}_{2}$ & & $46.9, C$ \\
\hline $7^{\prime}$ & 1.31 , overlap & $29.4, \mathrm{CH}_{2}$ & & $175.3, \mathrm{C}$ \\
\hline $8^{\prime}$ & 2.05 , overlap & $31.5, \mathrm{CH}_{2}$ & $1.64, \mathrm{~s}$ & 22.0, $\mathrm{CH}_{3}$ \\
\hline $9^{\prime}$ & 5.40, dd $(10.9,5.5)$ & $130.4, \mathrm{CH}$ & $1.06, \mathrm{~d}(7.2)$ & $11.7, \mathrm{CH}_{3}$ \\
\hline $10^{\prime}$ & $5.34, \mathrm{dd}(10.9,6.5)$ & $128.2, \mathrm{CH}$ & $0.88, \mathrm{~s}$ & $18.6, \mathrm{CH}_{3}$ \\
\hline $11^{\prime}$ & 2.74, overlap & $29.8, \mathrm{CH}_{2}$ & & \\
\hline $12^{\prime}$ & $5.34, \mathrm{dt}(10.9,6.5)$ & $128.1, \mathrm{CH}$ & & \\
\hline $13^{\prime}$ & 5.40, dd $(10.9,5.5)$ & $130.2, \mathrm{CH}$ & & \\
\hline $14^{\prime}$ & 2.05 , overlap & $29.5, \mathrm{CH}_{2}$ & & \\
\hline $15^{\prime}$ & 1.31 , overlap & $29.3, \mathrm{CH}_{2}$ & & \\
\hline $16^{\prime}$ & 1.31 , overlap & $25.2, \mathrm{CH}_{2}$ & & \\
\hline $17^{\prime}$ & 1.31 , overlap & $22.7, \mathrm{CH}_{2}$ & & \\
\hline $18^{\prime}$ & $0.89, \mathrm{t}(6.8)$ & $14.0, \mathrm{CH}_{3}$ & & \\
\hline $4-\mathrm{OH}$ & & & $4.36, \mathrm{~s}$ & \\
\hline 7-OH & & & $4.54, \mathrm{~d}(4.0)$ & \\
\hline
\end{tabular}

\subsection{Biological Activities of the Isolated Compounds}

The isolated compounds, as well as the hydrolysis products 6 and 7, were evaluated for antimicrobial activity [19] against nine human- and aqua-pathogenic bacteria, Aeromonas hydrophilia, Edwardsiella ictarda, E. tarda, Escherichia coli, Staphylococcus aureus, Vibrio alginolyticus, V. anguillarum, $V$. harveyi, and V. parahemolyticus, as well as four plant-pathogenic fungi, Alternaria solani, Ceratobasidium cornigerum, Colletotrichum glecosporioides, and Fusarium graminearum (Table 2). Compound $\mathbf{1}$ exhibited significant activity against Edwardsiella tarda and Ceratobasidium cornigerum, with MIC values of 0.25 and $0.5 \mu \mathrm{g} / \mathrm{mL}$, respectively, whereas one of its hydrolysis product 9,12-octadecadienoic acid (7) demonstrated activities against each of the tested pathogens, with MIC (minimum inhibitory 
concentration) values ranging from 1.0 to $8.0 \mu \mathrm{g} / \mathrm{mL}$. In contrast, compounds $2-6$ were inactive toward all pathogens in our experiments. These data indicated that the incorporation of a fatty acid into the acorane-type sesquiterpenoid derivative likely significantly increases the antimicrobial activity. The addition of a fatty acid could improve the penetration into the cell membrane, which may cause the antimicrobial activity [20].

Table 2. Antimicrobial activities of compounds 1-7 (MIC, $\mu \mathrm{g} / \mathrm{mL})^{\mathrm{a}}$.

\begin{tabular}{|c|c|c|c|c|}
\hline \multirow{2}{*}{ Strains } & \multicolumn{4}{|c|}{ Compounds } \\
\hline & 1 & $2-6$ & 7 & Positive Control \\
\hline A. hydrophilia b & - & - & 4.0 & 0.5 \\
\hline E. $\operatorname{tarda}$ b & 0.25 & - & 1.0 & 0.25 \\
\hline V. anguillarum ${ }^{\mathrm{b}}$ & - & - & 8.0 & 0.5 \\
\hline V. harveyi ${ }^{\mathrm{b}}$ & - & - & 4.0 & 2.0 \\
\hline V. parahemolyticus $\mathrm{b}$ & - & - & 4.0 & 1.0 \\
\hline C. cornigerum ${ }^{\mathrm{c}}$ & 0.5 & - & 8.0 & 0.5 \\
\hline
\end{tabular}

\section{Materials and Methods}

\subsection{General}

Optical rotations were measured on an Optical Activity AA-55 polarimeter (Optical Activity Ltd., Cambridgeshire, UK). UV spectra were measured on a PuXi TU-1810 UV-visible spectrophotometer (Shanghai Lengguang Technology Co. Ltd., Shanghai, China). ECD spectra were acquired on a JASCO J-715 spectropolarimeter (JASCO, Tokyo, Japan). Quantum chemical calculations were conducted using Gaussian 09 software. NMR spectra were recorded on a Bruker Avance 500 spectrometer (Bruker Biospin Group, Karlsruhe, Germany). Mass spectra were determined on a VG Autospec 3000 or an API QSTAR Pulsar 1 mass spectrometer (VG Instruments, London, UK). HPLC was performed using a Dionex HPLC system (Dionex, Sunnyvale, CA, USA) equipped with a P680 pump, an ASI-100 automated sample injector, and a UVD340U multiple wavelength detector controlled by Chromeleon software (version 6.80). Commercially available Si gel (200-300 mesh, Qingdao Haiyang Chemical Co., Qingdao, China), Lobar LiChroprep RP-18 (40-63 m, Merck, Darmstadt, Germany), and Sephadex LH-20 (18-110 $\mu \mathrm{m}$, Merck, Darmstadt, Germany) were used for open column chromatography. Solvents for extraction and purification were distilled prior to use.

\subsection{Fungal Material}

The fungus Penicillium bilaiae MA-267 was isolated from the rhizosphere of the marine mangrove plant Lumnitzera racemosa that was collected at Hainan Island, P. R. China, in March 2013. P. chermesinum EN-480 was isolated from the fresh tissue of marine red algal Pterocladiella tenuis, collected from Shandong province, P. R. China, in July 2014. The fungi were identified as Penicillium bilaiae and Penicillium chermesinum, respectively, by sequence analysis of the ITS (internal transcribed spacer) regions of their $18 \mathrm{~S}$ rDNA, as described previously [21]. The resulting sequence data obtained were deposited in GenBank (accession nos. KP096311 for P. bilaiae MA-267 and KT119566 for P. chermesinum EN-480). Both strains EN-480 and MA-267 are preserved at the Key Laboratory of Experimental Marine Biology, Institute of Oceanology of the Chinese Academy of Sciences.

\subsection{Fermentation}

P. bilaiae MA-267 and P. chermesinum EN-480 were each grown on PDA (potato dextrose agar) medium at $28^{\circ} \mathrm{C}$ for four days, and P. chermesinum EN-480 was then inoculated into $1 \mathrm{~L}$ conical flasks $(100 \times 100 \mathrm{~mL}$, a total of $10 \mathrm{~L})$, each containing $100 \mathrm{~mL}$ of rice medium $(70 \mathrm{~g}$ rice, $0.3 \mathrm{~g}$ peptone, $0.1 \mathrm{~g}$ 
corn syrup, and $100 \mathrm{~mL}$ naturally sourced and filtered seawater that was obtained from the Huiquan Gulf of the Yellow Sea near the campus of IOCAS) at room temperature. After 3 days, a full loop of P. bilaiae MA-267 was transferred aseptically to each flask culture of P. chermesinum EN-480 and re-incubated at room temperature for 28 days.

\subsection{Extraction and Isolation}

The fermented co-cultures of P. bilaiae MA-267 and P. chermesinum EN-480 were exhaustively extracted with EtOAc (150 mL/flask). The combined EtOAc solution was concentrated under reduced pressure to give an extract $(30 \mathrm{~g})$, which was fractionated by silica gel vacuum liquid chromatography (VLC) using different solvents of increasing polarity from petroleum ether (PE) to $\mathrm{MeOH}$ to yield ten fractions (Frs. 1-10), based on TLC (thin layer chromatography) analysis (developing solvents, $\left.\mathrm{CH}_{2} \mathrm{Cl}_{2}-\mathrm{MeOH}, 20: 1\right)$. Fraction 3 (1.5 g) was further purified by reversed-phase column chromatography (CC) over Lobar LiChroprep RP-18 with a MeOH- $\mathrm{H}_{2} \mathrm{O}$ gradient (from 20:80 to 100:0) to afford five subfractions (Fr. 3-1 to Fr. 3-5). Further purification of Fr. 3-3 by CC over silica gel with a $\mathrm{CH}_{2} \mathrm{Cl}_{2}-\mathrm{MeOH}$ gradient (from 80:1 to 10:1) and then on Sephadex LH-20 (MeOH) yielded compound 4 (10.8 mg) (Scheme 1). Fr.3-5 was further purified by CC over silica gel with a $\mathrm{CH}_{2} \mathrm{Cl}_{2}-\mathrm{MeOH}$ gradient (from 50:1 to 5:1), prep TLC (plate, $20 \mathrm{~cm} \times 20 \mathrm{~cm}$; developing solvents, petroleum ether-ethyl acetate, 5:1), and then on Sephadex LH-20 (MeOH) to yield compound 1 (12.1 mg). Fraction 5 (2.8 g) was further purified by reversed-phase column chromatography (CC) over Lobar LiChroprep RP-18 with a $\mathrm{MeOH}-\mathrm{H}_{2} \mathrm{O}$ gradient (from 20:80 to 100:0) to afford five subfractions (Fr. 5-1 to Fr. 5-5). Fr. 5-2 was further purified by Sephadex LH-20 (MeOH) and then prep TLC (plate, $20 \mathrm{~cm} \times 20 \mathrm{~cm}$; developing solvents, petroleum ether-ethyl acetate, 2:1) to afford compound 5 (11.8 mg). Fr. 5-3 was further purified by $\mathrm{CC}$ over silica gel with a $\mathrm{CH}_{2} \mathrm{Cl}_{2}-\mathrm{MeOH}$ gradient (from 60:1 to 10:1) and then on Sephadex LH-20 $(\mathrm{MeOH})$ to yield compound $3(12.9 \mathrm{mg})$. Further purification of fraction 7 (0.8 g) by CC over silica gel with a $\mathrm{CH}_{2} \mathrm{Cl}_{2}-\mathrm{MeOH}$ gradient (from 50:1 to 1:1) and then on Sephadex LH-20 (MeOH) yielded compound 2 (2.2 mg). Sesquiterpenes and spiromeroterpenoid derivatives were the major metabolites of P. bilaiae MA-267 and P. chermesinum EN-480 when cultured alone, as reported in our previous chemical investigations [9-11].

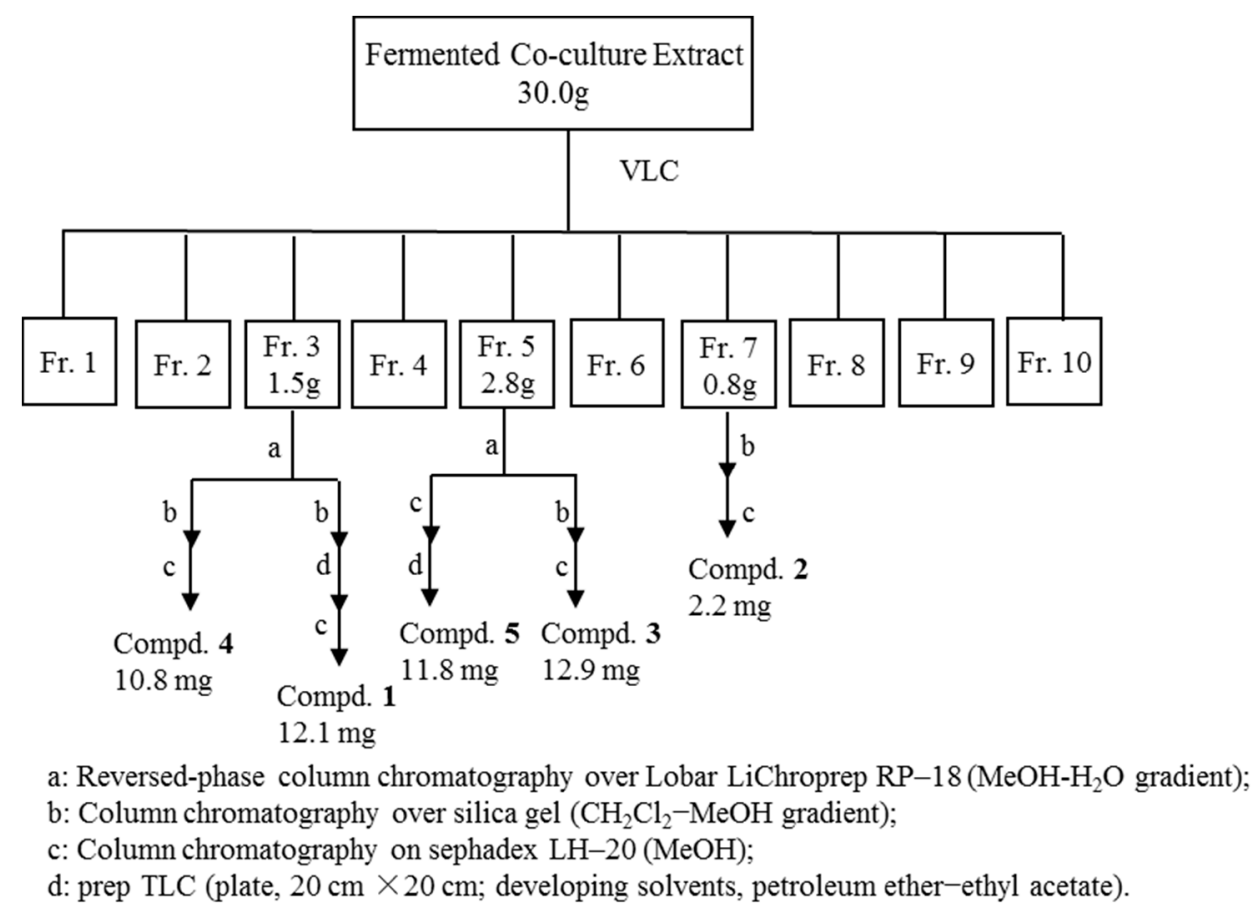

Scheme 1. Isolation procedure of compounds 1-5. 
Chermebilaene A (1): Colorless oil; $(\alpha)_{\mathrm{D}}^{20}:-5.25$ (c 0.05, MeOH); IR $v_{\max }$ 2957, 1991, 1734, 1620, 991 $\mathrm{cm}^{-1} ;{ }^{1} \mathrm{H}$ and ${ }^{13} \mathrm{C}$ NMR data, Table 1 ; HRESIMS $\mathrm{m} / z 558.4527\left(\mathrm{M}+\mathrm{NH}_{4}\right)^{+}\left(\right.$calcd for $\mathrm{C}_{35} \mathrm{H}_{60} \mathrm{O}_{4} \mathrm{~N}$, 558.4517), $m / z 563.4074(\mathrm{M}+\mathrm{Na})^{+}$(calcd for $\left.\mathrm{C}_{35} \mathrm{H}_{56} \mathrm{O}_{4} \mathrm{Na}, 563.4071\right)$.

Chermebilaene B (2): Colorless solid; $(\alpha)_{\mathrm{D}}^{20}:-40.00$ (c 0.08, MeOH); UV (MeOH) $\lambda_{\max }(\log \varepsilon) 202$ (3.6) $\mathrm{nm}$; IR $v_{\max } 3549,3378,2923,1803,1704,1385,1320,1064 \mathrm{~cm}^{-1}$; ECD (MeOH) $\lambda_{\max }(\Delta \varepsilon) 209(-2.7), 259$ $(-0.28) \mathrm{nm} ;{ }^{1} \mathrm{H}$ and ${ }^{13} \mathrm{C}$ NMR data, Table 1; HRESIMS $m / z 498.2684\left(\mathrm{M}+\mathrm{NH}_{4}\right)^{+}\left(\right.$calcd for $\mathrm{C}_{25} \mathrm{H}_{40} \mathrm{O}_{9} \mathrm{~N}$, 498.2698).

\subsection{Hydrolysis of Compound 1}

Compound $1(10.0 \mathrm{mg}, 18.5 \mu \mathrm{M})$ was dissolved in $5 \mathrm{~mL}$ of $\mathrm{THF} / \mathrm{MeOH} / \mathrm{H}_{2} \mathrm{O}(2 / 2 / 1)$ mixed solvent, to which an excess amount of lithium hydroxide $(10.5 \mathrm{mg}, 43.7 \mu \mathrm{M})$ was added. The reaction mixture was allowed to stir at room temperature for $36 \mathrm{~h}$ and was then evaporated to dryness under reduced pressure. The progress of the reaction was monitored by TLC analysis. The resulting reaction mixture was then dissolved in $2 \mathrm{~mL}$ of $10 \mathrm{wt} \% \mathrm{NaH}_{2} \mathrm{PO}_{4}$, extracted with dichloromethane $(3 \times 4 \mathrm{~mL})$, dried with $\mathrm{Na}_{2} \mathrm{SO}_{4}$, and then concentrated in vacuo to obtain the product.

\subsection{Antimicrobial Assay}

Antimicrobial assays against two human pathogens (Escherichia coli, Staphylococcus aureus), seven aquatic bacteria (Aeromonas hydrophilia, Edwardsiella ictarda, E. tarda, Vibrio alginolyticus, $V$. anguillarum, V. harveyi, and V. parahemolyticus), and four plant-pathogenic fungi (Alternaria solani, Ceratobasidium cornigerum, Colletotrichum glecosporioides, and Fusarium graminearum), was carried out by the 96-well microtiter plates assay [19]. The pathogens were obtained from the Institute of Oceanology, Chinese Academy of Sciences. Chloramphenicol and amphotericin B were used as positive controls for bacteria and fungi, respectively.

\section{Conclusions}

In summary, we isolated and identified two new meroterpenoid derivatives ( $\mathbf{1}$ and $\mathbf{2})$, as well as three known sesquiterpenoids (3-5), from the co-culture broth of two marine-derived fungi, P. bilaiae MA-267 and P. chermesinum EN-480, whereas neither fungus could produce these compounds when cultured alone. It is noteworthy that compound $\mathbf{1}$ represents an unprecedented acorane-type sesquiterpene hybridized with an octadecadienoic acid skeleton, and it may prove useful as an antibiotic agent against aquatic or plant pathogens. The fact that co-cultivation in the present study induced the production of new fungal metabolites with improved antimicrobial activity demonstrates the general value of such co-cultivation experiments and encourages future studies.

Supplementary Materials: The following are available online at http://www.mdpi.com/1660-3397/18/7/339/s1, Figure S1: HRESI mass spectrum of compound 1. Figure S2: ${ }^{1} \mathrm{H}$ NMR $\left(500 \mathrm{MHz}, \mathrm{CDCl}_{3}\right)$ spectrum of compound 1. Figure S3: ${ }^{13} \mathrm{C}$ NMR $\left(125 \mathrm{MHz}, \mathrm{CDCl}_{3}\right)$ and DEPT spectra of compound 1. Figure S4: COSY spectrum of compound 1. Figure S5: HSQC spectrum of compound 1. Figure S6: HMBC spectrum of compound 1. Figure S7: NOESY spectrum of compound 1. Figure S8: HRESI mass spectrum of compound 1. Figure S9: ${ }^{1} \mathrm{H}$ NMR (500 $\mathrm{MHz}$, DMSO- $\left.d_{6}\right)$ spectrum of compound 2. Figure S10: ${ }^{13} \mathrm{C}$ NMR $\left(125 \mathrm{MHz}, \mathrm{DMSO}-d_{6}\right)$ and DEPT spectra of compound 2. Figure S11: COSY spectrum of compound 2. Figure S12: HSQC spectrum of compound 2. Figure S13: HMBC spectrum of compound 2. Figure S14: NOESY spectrum of compound 2. Figure S15: ${ }^{1} \mathrm{H}$ NMR ( $500 \mathrm{MHz}$, DMSO- $\left.d_{6}\right)$ spectrum of compound 6. Figure S16: ${ }^{13} \mathrm{C}$ NMR (125 MHz, DMSO- $\left.d_{6}\right)$ and DEPT spectra of compound 6. Figure S17: COSY spectrum of compound 6. Figure S18: HMBC spectrum of compound 6. Figure S19: HMBC spectrum of compound 6. Figure S20: NOESY spectrum of compound 6. Figure S21: ${ }^{1} \mathrm{H}$ NMR $\left(500 \mathrm{MHz}\right.$, DMSO- $d_{6}$ ) spectrum of (S)-MTPA ester (6a). Figure S22: ${ }^{1} \mathrm{H}$ NMR (500 MHz, DMSO- $\left.d_{6}\right)$ spectrum of (R)-MTPA ester (6b).

Author Contributions: L.-H.M. performed the experiments and prepared the manuscript; X.-M.L. performed the 1D and 2D NMR experiments; H.-L.L. participated in the experiment; B.-G.W. supervised the research work and revised the manuscript. All authors have read and agreed to the published version of the manuscript. 
Funding: This work was funded by the Natural Science Foundation of China (Grant Nos. 31600267 and 41976090), and by the Qingdao National Laboratory for Marine Science and Technology (YQ2018NO08) and the project of Qingdao Science and Technology Bureau (18-2-2-59-jch). L.-H.M. thanks the Youth Innovation Promotion Association of the Chinese Academy of Sciences (2017250). B.-G.W. acknowledges the support of Taishan Scholar Project from Shandong Province.

Acknowledgments: The authors appreciate the High Performance Computing Environment Qingdao Branch of Chinese Academy of Science (CAS)-High Performance Computing Center of Institute of Oceanology of CAS for CPU time.

Conflicts of Interest: The authors declare no conflict of interest.

\section{References}

1. Carroll, A.R.; Copp, B.R.; Davis, R.A.; Keyzers, R.A.; Prinsep, M.R. Marine natural products. Nat. Prod. Rep. 2020, 37, 175-223. [CrossRef] [PubMed]

2. Imhoff, J.F. Natural products from marine fungi-Still an underrepresented resource. Mar. Drugs 2016, 14, 19. [CrossRef] [PubMed]

3. Barzkar, N.; Tamadoni, J.S.; Poorsaheli, H.B.; Vianello, F. Metabolites from marine microorganisms, micro, and macroalgae: Immense scope for pharmacology. Mar. Drugs 2019, 17, 464. [CrossRef] [PubMed]

4. Gross, H. Genomic mining-A concept for the discovery of new bioactive natural products. Curr. Opin. Drug Discov. Dev. 2009, 12, 207-219. [CrossRef]

5. Scherlach, K.; Hertweck, C. Triggering cryptic natural products biosynthesis in microorganisms. Org. Biomol. Chem. 2009, 7, 1753-1760. [CrossRef] [PubMed]

6. Ueda, K.; Beppu, T. Antibiotics in microbial coculture. J. Antibiot. 2017, 70, 361-365. [CrossRef] [PubMed]

7. Marmann, A.; Aly, A.H.; Lin, W.; Wang, B.; Proksch, P. Co-Cultivation-A powerful emerging tool for enhancing the chemical diversity of microorganisms. Mar. Drugs 2014, 12, 1043. [CrossRef] [PubMed]

8. Meng, L.H.; Liu, Y.; Li, X.M.; Xu, G.M.; Ji, N.Y.; Wang, B.G. Citrifelins A and B, citrinin adducts with a tetracyclic framework from cocultures of marine-derived isolates of Penicillium citrinum and Beauveria felina. J. Nat. Prod. 2015, 78, 2301-2305. [CrossRef] [PubMed]

9. Meng, L.H.; Li, X.M.; Liu, Y.; Wang, B.G. Penicibilaenes A and B, sesquiterpenes with a tricyclo[6.3.1.0 $0^{1,5}$ ]dodecane skeleton from the marine isolate of Penicillium bilaiae MA-267. Org. Lett. 2014, 16, 6052-6055. [CrossRef] [PubMed]

10. Liu, H.; Li, X.M.; Liu, Y.; Zhang, P.; Wang, J.N.; Wang, B.G. Chermesins A-D: Meroterpenoids with a drimane-type spirosesquiterpene skeleton from the marine algal-derived endophytic fungus Penicillium chermesinum EN-480. J. Nat. Prod. 2016, 79, 806-811. [CrossRef] [PubMed]

11. Hu, X.Y.; Li, X.M.; Yang, S.Q.; Liu, H.; Meng, L.H.; Wang, B.G. Three new sesquiterpenoids from the algal-derived fungus Penicillium chermesinum EN-480. Mar. Drugs 2020, 18, 194. [CrossRef] [PubMed]

12. Lee, J.H.; Lee, K.R. Phytochemical constituents of Cirsium nipponicum (MAX.) Makino. Kor. J. Pharmacogn. 2005, 36, 145-150.

13. Liu, Y.; Li, X.M.; Meng, L.H.; Jiang, W.L.; Xu, G.M.; Huang, C.G.; Wang, B.G. Bisthiodiketopiperazines and acorane sesquiterpenes produced by the marine-derived fungus Penicillium adametzioides AS-53 on different culture media. J. Nat. Prod. 2015, 78, 1294-1299. [CrossRef] [PubMed]

14. Ishikawa, K.; Sato, F.; Itabashi, T.; Wachi, H.; Takeda, H.; Wakana, D.; Yaguchi, T.; Kawai, K.; Hosoe, T. Asnovolins A-G, spiromeroterpenoids isolated from the fungus Aspergillus novofumigatus, and suppression of fibronectin expression by asnovolin E. J. Nat. Prod. 2016, 79, 2167-2174. [CrossRef] [PubMed]

15. Frisch, M.J.; Trucks, G.W.; Schlegel, H.B.; Scuseria, G.E.; Robb, M.A.; Cheeseman, J.R.; Scalmani, G.; Barone, V.; Mennucci, B.; Petersson, G.A.; et al. Gaussian 09, Revision D.01; Gaussian, Inc.: Wallingford, CT, USA, 2013.

16. Zhang, G.J.; Li, Y.H.; Jiang, J.D.; Yu, S.S.; Wang, X.J.; Zhuang, P.Y.; Zhang, Y.; Qu, J.; Ma, S.G.; Li, Y.; et al. Diterpenes and sesquiterpenes with anti-coxsackie virus B3 activity from the stems of Illicium jiadifengpi. Tetrahedron 2014, 70, 4494-4499. [CrossRef]

17. Yue, Q.; Miller, C.J.; White, J.F., Jr.; Richardson, M.D. Isolation and characterization of fungal inhibitors from Epichloë festucae. J. Agric. Food Chem. 2000, 48, 4687-4692. [CrossRef] [PubMed]

18. Granica, S.; Lohwasser, U.; Jöhrer, K.; Zidorn, C. Qualitative and quantitative analyses of secondary metabolites in aerial and subaerial of Scorzonera hispanica L. (black salsify). Food Chem. 2015, 173, 321-331. [CrossRef] [PubMed] 
19. Pierce, C.G.; Uppuluri, P.; Tristan, A.R.; Wormley, F.L., Jr.; Mowat, E.; Ramage, G.; Lopez-Ribot, J.L. A simple and reproducible 96-well plate-based method for the formation of fungal biofilms and its application to antifungal susceptibility testing. Nat. Protoc. 2008, 3, 1494-1500. [CrossRef] [PubMed]

20. Watanabe, T.; Yamamoto, Y.; Miura, M.; Konno, H.; Yano, S.; Nonomura, Y. Systematic analysis of selective bactericidal activity of fatty acids against Staphylococcus aureus with minimum inhibitory concentration and minimum bactericidal concentration. J. Oleo Sci. 2019, 68, 291-296. [CrossRef] [PubMed]

21. Wang, S.; Li, X.M.; Teuscher, F.; Li, D.L.; Diesel, A.; Ebel, R.; Proksch, P.; Wang, B.G. Chaetopyranin, a benzaldehyde derivative, and other related metabolites from Chaetomium globosum, an endophytic fungus derived from the marine red alga Polysiphonia urceolata. J. Nat. Prod. 2006, 69, 1622-1625. [CrossRef] [PubMed]

(C) 2020 by the authors. Licensee MDPI, Basel, Switzerland. This article is an open access article distributed under the terms and conditions of the Creative Commons Attribution (CC BY) license (http://creativecommons.org/licenses/by/4.0/). 